\title{
Effects of endocrine disruptors in the development of the female reproductive tract
}

\author{
Efeitos dos desreguladores endócrinos no \\ desenvolvimento do trato reprodutivo feminino
}

Elaine Maria Frade Costa', Poli Mara Spritzer²,

Alexandre Hohl'3 ${ }^{3}$ Tânia A. S. S. Bachega ${ }^{4}$

\begin{abstract}
Environmental agencies have identified a growing number of environmental contaminants that have endocrine disrupting activity, and these can become a major public health problem. It is suggested that endocrine disruptors could account for the higher-than-expected increase in the prevalence of some non-communicable diseases, such as obesity, diabetes, thyroid diseases, and some cancers. Several endocrine Disrupting Chemicals (EDCs), such as pesticides, bisphenol A, phthalates, dioxins, and phytoestrogens, can interact with the female reproductive system and lead to endocrine disruption. Initially, it was assumed that EDCs exert their effects by binding to hormone receptors and transcription factors, but it is currently known that they may also alter the expression of enzymes involved in the synthesis or catabolism of steroids. Biomonitoring studies have identified these compounds in adults, children, pregnant women, and fetuses. Among the diseases of the female reproductive tract associated with EDCs exposure are the following: precocious puberty, polycystic ovary syndrome, and premature ovarian failure. The different populations of the world are exposed to a great number of chemicals through different routes of infection; despite the various available studies, there is still much doubt regarding the additive effect of a mixture of EDCs with similar mechanisms of action. Arq Bras Endocrinol Metab. 2014;58(2):153-61
\end{abstract}

\section{Keywords}

Endocrine disruptors; female development; precocious puberty; polycystic ovary syndrome; premature ovarian failure

\section{RESUMO}

As diversas agências de controle ambiental têm identificado um crescente número de contaminantes ambientais que apresentam atividade de desregulador endócrino e estes poderão se tornar um dos maiores problemas de saúde pública. Sugere-se que os Desreguladores Endócrinos (EDCs) poderiam justificar o aumento na prevalência de algumas doenças não transmissíveis acima do esperado, como, por exemplo, obesidade, diabetes, doenças tireoidianas e alguns tipos de cânceres. Vários EDCs, como pesticidas, bisfenol A, ftalatos, dioxinas e fitoestrógenos, podem interagir com o sistema reprodutivo feminino e levar à desregulação endócrina. Inicialmente, supunha-se que os EDCs exercessem seus efeitos através da ligação com receptores hormonais e fatores de transcrição, mas, atualmente, sabe-se que também podem alterar a expressão de enzimas envolvidas na síntese ou no catabolismo dos esteroides. Estudos de biomonitoramento têm identificado esses compostos em adultos, crianças, gestantes e em fetos. Entre as patologias do trato reprodutor feminino associadas à exposição aos EDCs, destacam-se: puberdade precoce, síndrome dos ovários policísticos e falência ovariana prematura. As diversas populações estão expostas a um grande número de substâncias químicas, através de diferentes vias de contaminação. Apesar dos diferentes estudos disponíveis, ainda permanece uma grande dúvida sobre o efeito aditivo de uma mistura de EDCs com similar mecanismo de ação. Arq Bras Endocrinol Metab. 2014;58(2):153-61

\section{Descritores}

Desreguladores endócrinos; desenvolvimento feminino; puberdade precoce; síndrome dos ovários policísticos; falência ovariana prematura
Unidade de Endocrinologia do Desenvolvimento, Laboratório de Hormônios e Genética Molecular LIM42, Disciplina de Endocrinologia e Metabologia, Hospital das Clínicas, Faculdade de Medicina da Universidade de São Paulo (HC-FMUSP), São Paulo, SP, Brazil

${ }^{2}$ Divisão de Endocrinologia,

Unidade de Ginecologia Endócrina, Hospital de Clínicas de Porto Alegre, Departamento de Fisiologia, Laboratório de Endocrinologia Molecular, Universidade Federal do Rio Grande do Sul (UFRGS) Porto Alegre, RS, Brazil

${ }^{3}$ Serviço de Endocrinologia e Metabologia do Hospital Universitário, Universidade Federal de Santa Catarina (UFSC), Florianópolis, SC, Brazil

${ }^{4}$ Unidade de Adrenal, Laboratório de Hormônios e Genética Molecular LIM42, Disciplina de Endocrinologia e Metabologia, HC-FMUSP, São Paulo, SP, Brazil

Correspondence to: Tânia A. S. S. Bachega Laboratório de Hormônios Genética Molecular/LIM42 Hospital das Clínicas, Faculdade de Medicina, Universidade de São Paulo Av. Dr. Enéas de Carvalho Aguiar, $155,2^{\circ}$ andar, Bloco 6 05403-900 - São Paulo, SP, Brazil tbachega@usp.br

Received on Oct/1/2013 Accepted on Dec/2/2013 


\section{INTRODUCTION}

$I^{n}$ $\mathrm{n}$ an era focused on sustainability, environment preservation is an international concern, since large amounts of chemicals have been released to the environment, especially after the expansion of the industrial revolution. These chemicals are known as Emerging Organic Contaminants (EOCs), and many of them can alter the normal balance of endocrine systems. Because of this, this latter group of chemicals has been termed Endocrine Disrupting Chemicals (EDCs) (1).

A number of environmental agencies worldwide have identified a growing number of environmental contaminants that have endocrine disrupting activity. Currently, these data have been one of the greatest public health concerns. It has been suggested that EDCs could explain the higher-than-expected increasing prevalence of some diseases in growing populations, such as diabetes, infertility, thyroid diseases, and some cancers (2). Considering the increasing prevalence of obesity, it has been assumed that the presence of chemicals in the environment could predispose to its development in addition to the classic etiologic factors, such as increasing consumption of high caloric foods, and a sedentary lifestyle. All this evidence can help us better understand the mechanisms by which EDCs can alter hormonal control of the metabolism and how they contribute to the ontogeny of diseases, which is of great importance for the health of populations and for environmental management.

EDCs can originate naturally from plants or animals; however, artificial chemical compounds have currently been the main concern all over the world. EDCs potentially interfere with the production, secretion, metabolism, transport or peripheral action of endogenous hormones by means of their binding to hormone receptors (2). After binding to the receptors, the EDCs can trigger two types of response: mimicking hormonal action, which is called an agonistic effect, or leading to a lack of response and preventing the binding of the natural hormone, which is called antagonistic effect.

Initially, it was thought that EDCs worked only by binding to hormone receptors; however, currently it is known that EDCs may act by recruiting of coactivators or correpressors in enzymatic pathways, altering hormone synthesis, metabolism pathways, modifying plasmatic clearance, or acting directly on gene expression by means of epigenetic modifications without changing the nucleotide sequences $(1,3)$. The main example of epigenetic modification is the methylation of cytosine residues in the promoter regulatory regions, which means the takeover of a methyl group at the $5^{\text {th }}$ carbon of a cytosine followed by a guanine chain, and resulting in aberrant gene silencing. This is the causative mechanism of many diseases, such as tumor development (3). A classic example of epigenetic effect secondary to EDCs was demonstrated after exposure of pregnant women to diethylstilbestrol (DES), used to prevent miscarriages. It was observed that female fetuses exposed in the first trimester of pregnancy had a higher incidence of infertility in adult life, and higher incidence of vaginal clear cell carcinoma. The highest incidence of reproductive disorders was observed in the second generation of these women exposed to DES in utero, suggesting that epigenetic changes can be transmitted to subsequent generations (4).

Based on the data above, the United State Environmental Protection Agency (EPA) proposed a broader definition for endocrine disruptors, which also considers the wide diversity of mechanisms involved in endocrine dysfunctions. The agency describes an endocrine disrupting chemical as an exogenous substance, or mixture that alters one or more functions of the endocrine system, as well as its structure, causing adverse effects on both the exposed organism and its offspring (1).

For many years, toxicologists believed that the EDCs toxic effects were directly proportional to the ingested dose (monotonic curve); however, several studies refute this concept. It has been suggested that, similar to the hormones, EDCs have a biphasic, U-shaped, or inverted-U dose response curve (i.e., dose-response curve is not monotonic). Hence, very low doses could have significant effects on cell proliferation or development (3).

In addition, exposure to EDCs during the developmental period is an important factor. Although exposure of adult populations may cause damage to health, exposure of fetuses and infants is even more relevant, since the susceptibility to the adverse effects of EDCs is much higher during these periods. These harmful effects during developmental periods may occur with exposure to much lower doses than those considered harmful to adults (3). The reasons for this increased sensitivity could be explained by the lack of protective mechanisms generally present in adults, such as mechanism of DNA repair, presence of efficient detoxifying enzymes, liver maturity enabling serum clearance of chemical compounds, and the protection of the blood-brain barrier.

Consequently, the period in which the exposure to EDCs occurs has a crucial role in its toxicity. Fetal exposure may modify the cellular and tissue development as part of fetal programming of diseases in adulthood; 
for example, diseases of reproductive tract and metabolic diseases. Beyond the fetal period, other periods of increased sensitivity to the effects of EDCs include childhood and adolescence (5).

\section{MAJOR CHEMICAL COMPOUNDS WITH ENDOCRINE DISRUPTING ACTIVITY}

A wide variety of chemical compounds with endocrine disruption activity has been recognized by environmental agencies around the world, including pesticides, pollutants and substances used in plastic manufacturing (Table 1). EDCs can be classified according to their use, (e.g., pesticides), or to its structural property, (e.g., dioxins, steroids, and polyaromatic hydrocarbons). All

Table 1. Some of chemicals worldwide recognized as Endocrine Disrupting Chemicals

\begin{tabular}{|c|c|c|c|c|}
\hline \multirow{2}{*}{ Chemicals } & \multicolumn{4}{|c|}{ Environmental agency } \\
\hline & UKEA & USEPA & OSPAR & JEA \\
\hline \multicolumn{5}{|l|}{ Steroids } \\
\hline Ethinylestradiol & $x$ & & $x$ & \\
\hline 17 $\beta$-Estradiol & $x$ & & $x$ & \\
\hline Estrone & $x$ & & $x$ & \\
\hline Mestranol & $x$ & & $x$ & \\
\hline Diethylstilbestrol & $x$ & & $x$ & \\
\hline \multicolumn{5}{|l|}{ Alkylphenols } \\
\hline Nonylphenol & $x$ & $x$ & $x$ & $x$ \\
\hline Nonylphenol ethoxylate & $x$ & & $x$ & \\
\hline Octylphenol & $x$ & $x$ & $x$ & $x$ \\
\hline Octylphenol ethoxylate & $x$ & & & \\
\hline \multicolumn{5}{|l|}{ Polyaromatic hydrocarbons } \\
\hline Polychlorinated biphenyls & $x$ & $x$ & $x$ & $x$ \\
\hline Flame retardants & & & $x$ & $x$ \\
\hline PAH & & $x$ & $x$ & \\
\hline \multicolumn{5}{|l|}{ Oxygenated compounds } \\
\hline Phthalates & $x$ & $x$ & $x$ & $x$ \\
\hline Bisphenol A & $x$ & $x$ & & $x$ \\
\hline \multicolumn{5}{|l|}{ Pesticides } \\
\hline Atrazine & $x$ & $x$ & $x$ & $x$ \\
\hline Endosulfan & $x$ & $x$ & $x$ & $X$ \\
\hline Lindane & $x$ & $x$ & $x$ & \\
\hline Hexachlorobenzene & $x$ & & $x$ & $x$ \\
\hline Pentachlorophenol & $x$ & $x$ & & $X$ \\
\hline \multicolumn{5}{|l|}{ Other } \\
\hline Dioxins and furans & $x$ & & $x$ & $x$ \\
\hline
\end{tabular}

PAH: polycyclic aromatic hydrocarbons, UKEA: UK Environmental Agency, USEPA: Environmental Protection Agency of the United States, OSPAR: Oslo and Paris Commission, JEA: Environmental Agency of Japan. Adapted from Costa and cols. (49). of them are widely found in the environment and may even be transported over long distances. In addition, a number of EDCs can be stored for several years in the fatty tissue of humans and animals, while others are quickly eliminated from the body. However, they can still cause serious effects, if exposure occurs during critical periods of development (3).

Below, some of the chemicals that have endocrine disrupting activity and are emphasized in the scientific literature will be discussed in detail.

\section{Plastics}

Due to their low cost of production, variety and durability, plastics have an important place in modern life. Their worldwide production exceeded 300 million tons in 2012 (3). Despite their importance, there are many controversies about the possible adverse effects of plastic components on human health, or even plastic additive compounds, with particular emphasis on phthalates and bisphenol $\mathrm{A}$.

Bisphenol A (BPA) is one of the chemical compounds of highest production worldwide: more than 6 billion pounds are produced annually (6). BPA is a monomer used in the production of polycarbonate plastics and epoxy resin covering the inside surface of food cans. After polymerization, some BPA molecules remain unbound and can migrate and contaminate foods and drinks. BPA can also be used as a dental sealant, and as an additive in other plastics, such as PVC and halogenated derivatives, which are widely used as flame retardants.

Human BPA exposure is widespread; it has been identified in about $95 \%$ of urine samples of the American population. BPA has also been identified in the serum of pregnant women, in the amniotic fluid and in umbilical cord blood at birth, indicating human exposure during one of the windows of increased susceptibility, the prenatal period $(3,6)$. It is estimated that the use of BPA by the ingestion of foods packaged in cans that are coated internally with epoxy resin, is around $6.6 \mathrm{mg} /$ person/day (6).

Among the BPA endocrine disrupting effects, the most recognized are on thyroid hormones and its estrogenic and adipogenic activities; consequently, it has been debatable that there are possible adverse effects of BPA exposure on human health. Several studies find an association between serum and urinary BPA concentrations with increased prevalence of hypothyroidism, infertility, cardiovascular disease, and diabetes (6). 
Phthalates are plasticizers used as softeners, because they determine flexibility, suppleness, and elasticity of rigid polymers, such as PVC. They have been produced in large quantities since the 1930s, and are also found in most industrial paints, solvents, toys, personal and medical care products, such as cosmetics and blood transfusion bags. The main routes of human contamination are food and skin absorption; exposure during the early stages of development can occur by transplacental route and during breastfeeding (6).

Among all phthalates, the most worrisome is DEHP, Di (2-ethylhexylphthalate), whose annual production exceeds 2 million tons. Studies with low doses of DEHP in mice identified toxicity to the reproductive system and increased proliferation and differentiation of adipocytes, which predisposes to visceral obesity (7). In humans, epidemiological studies suggest a correlation between phthalate concentrations in cord blood and lower gestational age at delivery (6).

\section{Dioxins}

Dioxins comprise a group of organochlorine compounds including polychlorinated dibenzodioxins (PCDDs), polychlorinated dibenzofurans (PCDFs), and polychlorinated biphenyls (PCBs). The PCDDs and PCDFs are not produced commercially, but they are present in compound impurities from the production of other chemicals, such as PCBs. These are used as insulators, flame-retardants, lubricants, and machine and transformer fluids. Dioxins are also formed during combustion processes, such as waste incineration and in smelting and refining of metals (8).

Another group of dioxins are polybrominated diphenyl ethers (PBDE), which are used primarily as flame-retardants. Whereas these compounds are added to some products, rather than chemically bound, they easily release material and still contaminate the environment. PBDEs also have bioaccumulation properties, and studies with human biological materials found that their concentrations have risen, especially in children, making it essential to carry out studies to assess the endocrine toxicity (6).

Dioxins are fat-soluble and easily contaminate the food chain by accumulating in adipose tissue. The main source of human exposure to dioxins and PCBs are foods of animal origin (9). In addition, dioxins are not readily metabolized and excreted and have a long halflife, about 8 years in case of TCDD (2,3,7,8-tetrachlorodibenzo-p-dioxin).
Several studies have evaluated the effects of human exposure to dioxins. In Vietnam War, veterans exposed to Agent Orange revealed increased prevalence of several types of cancers, degenerative diseases of the central nervous system, thyroid diseases, and disorders of sexual development. Exposure to dioxins leads to deleterious effects on reproductive functions by both antiestrogenic and anti-androgenic activities in animals, and carcinogenic activity was also demonstrated (3).

\section{Organotins}

Organotins, persistent organic pollutants, are being widely used in agriculture as fungicides, rodent repellents, and ship hull paints; they are also used as stabilizers for plastics, such as PVC.

Human exposure to organotins occurs mainly by food sources: contaminated fish, oysters, or water. Contamination by chloride tributyltin (TBT) may be associated with effects on male and female reproductive tracts and, recently, its association with adipogenic effects has also been discussed (10).

\section{Pesticides}

Human exposure to pesticides is ubiquitous, and recent an UK study reported that there are approximately 127 pesticides that have endocrine disrupting activity. Among the classes of pesticides that stand out are organophosphates, carbamates, and organochlorines. The latter is very persistent in the environment. Although dichlorodiphenyltrichloroethane (DDT) has been banned in most developed countries, human contamination is still identified in samples from adipose tissue and breast milk (10).

Atrazine is the most commonly detected pesticide contaminant of ground water and surface water. It is also an endocrine disruptor that, among other effects, alters reproductive tissues when animals are exposed during development (11).

Although EDCs may interfere with the endocrine system as a whole, many of the effects in humans are due to changes in estrogen signaling, one of the most conserved pathways in the evolution of the species. Anti-androgenic and anti-thyroid activities are well-known and can determine changes in the reproductive system, sexual differentiation and puberty, when exposure occurred in early embryonic development (12).

This paper will discuss some of the effects of EDCs on female reproductive development. 


\section{Pubertal development}

Over the past century, the average age of menarche has diminished in all the socioeconomic and ethnic groups, from 16 or 17 years to less than 13. Regarding telarche, there is even stronger evidence that its onset is also occurring earlier (13). Besides the possibility of psychological disturbances, precocious puberty is associated with a greater prevalence of various co-morbidities, among of which are: insulin resistance, metabolic syndrome, breast and reproductive system cancers (14).

It is widely known that nutritional factors influence the onset of puberty; however, in spite of the global epidemic of obesity, only increased body mass index does not justify this finding. Also, an increase in the frequency of cases of central idiopathic precocious puberty has been observed. For these data, besides the known influence of genetic and nutritional factors that trigger puberty, environmental effects are also discussed. From this discussion, the influence of EDCs is a noteworthy finding. These compounds act by binding to the estrogen receptor or by post-receptor signaling. Additionally, EDCs may also act in the brain by stimulating hypothalamic neurons, thereby releasing kisspeptin and promoting the maturation of the hypothalamus, causing earlier onset of puberty, or even precocious puberty (15).

The consumption of soy milk formulas, due to the presence of phytoestrogens, has been associated with precocious telarche (13). Some EDCs, such as DES, polybrominated biphenyls, DDT, DDE, and phthalates have also been associated with increased prevalence of precocious puberty in humans. Interestingly, exposure during the prenatal period may change developmental programming, and be associated with pubertal development afterwards without the need of a second exposure (16).

\section{Reproductive tract}

The differentiation of germ cells in the ovaries begins in the first trimester of intrauterine life; later, between the second and third quarter, they form primordial follicles, and afterwards, the follicles enter a latency period that can last from 15 to 50 years old in women. The oocytes are non-degenerate cells with a longer life in the human body, and consequently they are exposed to the effects of the environment during the entire period of their existence.

The correct formation of ovarian follicles in the fetus depends on a balance between systemic concentrations of estrogen, inhibin and activin. Therefore, estrogen exposure during the critical period of formation of follicles can change follicular dynamics. A classic example of the effects of EDCs on the ovaries is the identification of multioocyte follicles (MOF) in alligators inhabiting a lake in California; these animals were exposed during the early phases of the development to estrogenic compounds (17). This finding shows that maintenance of homeostasis of local and systemic hormones during follicle formation is required for normal development and subsequent maintenance of the quality of the oocyte. However, the mechanism by which endocrine disruptors alter folliculogenesis and have an impact on ovarian function in adult women remains unknown.

Assuming the hypothesis that EDCs contribute to the development of ovarian disease and thus reduce conception rates, two questions must be considered: what are the ovarian structures that would be target of EDCs? How do these changes are manifested? The reproductive disorders that may be related to these issues are: aneuploidy, polycystic ovary syndrome, primary ovarian failure, and changes in the menstrual cycle and in fecundability.

\section{Aneuploidy}

Several years ago, it was observed that mice that lived in damaged cages made of plastic with polycarbonates had a high incidence of meiotic changes in oocytes, and this observation led to the investigation of the estrogenic effects of the plasticizer bisphenol A (BPA) on oocytes (18). The authors concluded that BPA came from the water consumed by the animals. When they were maintained in intact cages and received water with BPA, similar changes in oocytes were also found, and some of these meiotic changes have resulted in aneuploidies (Table 2).

Table 2. Ovarian changes related to exposure to Endocrine Disrupting Chemicals

\begin{tabular}{ll}
\hline Endocrine disruptors & Ovarian changes \\
\hline BPA & Aneuploidy \\
Androgens, BPA, overnutrition, & PCOS \\
BPA, parabens, & POF \\
Pesticides, BPA, genistein, dioxins, & Menstrual irregularity and changes in \\
furans, biphenols & fecundability \\
\hline
\end{tabular}

BPA: bisphenol A; PCOS: polycystic ovary syndrome; POF: primary ovarian failure.

Experimental studies of different researchers conclude that BPA exposure has a deleterious impact on oocyte maturation, and BPA and other EDCs may 
cause similar meiotic changes in adult animals. However, changes also occur with exposure to significantly higher doses of BPA, during the fetal period of oogenesis. It is suggested that these effects may be due to the interference of BPA on estrogen receptor $\beta$ (ERb) (19).

\section{Primary ovarian failure}

Primary ovarian failure (POF) occurs in about $1 \%$ of the female population under 40 years of age, leading to reproductive disorders, early symptoms of menopause and other comorbidities (20). There are three possible mechanisms involved in the development of POF, including acceleration of apoptosis, blockage of follicle maturation and premature activation of the follicle. Several causes have been studied and may have some association with EDCs: (a) chromosomal abnormalities or genetic mutations, mainly involving the $\mathrm{X}$ chromosome, such as the premutation in FMR 1, (b) metabolic disorders such as galactosemia and 17-hydroxylase deficiency, (c) virus infection, such as HIV, (d) iatrogenic causes: radiotherapy or chemotherapy, (e) autoimmune causes, (f) other factors: smoking, toxins, and other environmental factors. The cause of most cases of POF is not identified, and it is believed to be multifactorial (21).

Many EDCs lead to multioocyte follicles (MOF), a potential precursor of premature ovarian failure, with the process being mediated by ERb agonist actions (22). After the administration of BPA to pregnant mice at doses of $0.1-1,000 \mu \mathrm{g} / \mathrm{kg}$ between the $9^{\text {th }}$ and $16^{\text {th }}$ day of pregnancy, the appearance of ovarian cysts was observed in adulthood, which were significantly more numerous in the group that received $1 \mu \mathrm{g} / \mathrm{kg}$ BPA. Moreover, cystic adenomas were observed in the groups receiving higher doses, but not in the controls; these data support the hypothesis that BPA causes adverse effects on the reproductive system, if exposure occurs during critical periods of differentiation (23). The doses used in this study are relevant for human exposure, since the estimated daily dose intake of BPA in the infant's formula is around 1 to $13 \mathrm{mg} / \mathrm{kg}$. The increased expression of genes involved in ovarian meiosis can explain the effects of BPA on female germ cells (24).

Another example of EDC that can affect folliculogenesis are parabens, which stimulate mRNA expression of anti-Mullerian hormone, and thus may inhibit the early stage of folliculogenesis in ovaries of newborn rats. In addition, parabens may regulate steroidogenesis by inhibiting follicular Foxl2, the main transcriptional repressor (25).

The compound 4-vinylcyclohexene diepoxide (VCD) is considered an occupational chemical ovotoxic (26). Repeated doses of VCD may accelerate the apoptotic process of atresia and selectively destroy primordial and primary follicles in rats and mice (27). Therefore, women exposed to VCD are considered at risk of POF.

Methoxychlor (MXC) is an organochlorine pesticide used as a substitute for DDT. MXC is an estrogenic compound that was demonstrated to have lower binding affinity for the estrogen receptor (28). The major MXC metabolites, HPTE [2, 2-bis-(p-hydroxyphenyl)-1, 1, 1- trichloroethane] and mono-OH MXC, have estrogenic, anti-estrogenic, or anti-androgenic actions (29). Studies have demonstrated that adult mice and rats that were exposed to MXC showed inhibition of growth and implantation of embryo and ovarian atrophy due to inhibition of folliculogenesis, leading to reduced atretic follicles and ovulation (30).

Diethylstilbestrol is a synthetic non-steroidal estrogen that was prescribed to pregnant women at doses of $5-150 \mathrm{mg} /$ day to prevent abortions between the years 1940-1970. Many reproductive abnormalities, both cardiovascular and immunological, were reported in male and female offspring of women treated with DES, and were validated in animal models (31). Recent studies have shown that neonatal exposure to $3 \mu \mathrm{g} / \mathrm{kg}$ DES induces MOF (22).

\section{Menstrual irregularity and fecundability}

Interference in the hormonal regulation of the menstrual cycle results in irregular or long cycles that will reduce fecundity (ability to conceive in a menstrual cycle). Studies in humans suggest that fetal and neonatal exposure to EDCs can change menstrual cycles due to hormonal interference (32). Exposure to organochlorine pesticides may make menstrual cycles shorter (33). Moreover, women who are exposed to non-organochlorine pesticides have 60 to $100 \%$ higher risk of developing long cycles or absence of menstrual cycles (34). Animal studies support the findings in humans; in utero exposure to estrogenic compounds, such as BPA or phytoestrogens, increases the duration of the estrous cycle in adult mice, and perinatal exposure to BPA causes irregular cycles and early suspension of cyclic activity (35). These changes are likely to occur due 
to a change in hypothalamic control of $\mathrm{LH}$ secretion and ovulation (36).

A recent Brazilian study quantified organochlorine compounds in infertile women and compared them to a control group of fertile women. Exposure to organochlorine compounds was most prevalent in infertile women, confirming the data from literature, indicating that dichlorodiphenyldichloroethylene (pp'DDE) may negatively affect female fertility (37).

\section{Polycystic ovary syndrome}

Polycystic ovary syndrome (PCOS) is a prevalent endocrine disorder in women and, in its classical presentation, is characterized by chronic anovulation and hyperandrogenism. More recently, some milder phenotypes have been recognized, in which either anovulation or hyperandrogenism may be absent. Frequently, these women present a characteristic polycystic ovarian appearance at ultrasound and high prevalence of obesity, insulin resistance, and metabolic comorbidities, mainly in its classical phenotype.

While the pathogenesis of PCOS is still not well established, evidence suggests that both genetic and environmental factors may contribute to the clinical development of the disease. Among these, BPA, an endocrine disruptor with well-known estrogen-like actions, has been implicated in its development (38).

In fact, studies in animal models have shown that BPA acts in different ways to disturb reproductive functions, including both estrogen and androgen pathways. BPA in vitro increases testosterone synthesis in rat ovarian theca-intersticial cells (39), and in male rats, it seems to compete with endogenous androgens for binding on sex hormone-binding globulin (SHBG), increasing serum free androgen levels. BPA also has been demonstrated to decrease hepatic androgen-related hydroxylases, inhibiting testosterone degradation, with an expected increase in hormone levels (40). Moreover, neonatal exposure to BPA could result in PCOS development (4l). Additionally, BPA may disturb insulin action and glucose metabolism contributing to insulin resistance in intact animals (42).

In humans, studies have reported higher BPA circulating levels in anovulatory women (38) and in PCOS patients (43), in comparison with controls. The mechanisms behind this association between BPA and PCOS are not clear but may be, at least in part, linked to androgen secretion, as suggested by data on animal studies. In this sense, BPA was found to be positively corre- lated with androgen levels in PCOS women, suggesting an additive effect of BPA in an individual genetically susceptible to an ovarian enzymatic defect (43).

In turn, dietary products have been emerging, as other environmental factors associated with the development of PCOS in susceptible individuals. Advanced glycated end-products (AGEs) are reactive derivatives of non-enzymatic glucose-protein reactions. AGEs are endogenously produced by aging, hyperglycemia, and oxidative stress, or exogenously ingested mainly from high-temperature processed, protein-rich foods (44). AGEs promote oxidative stress and insulin resistance in peripheral tissues by activating protein kinase C (45).

Serum AGEs levels are increased in women with PCOS, and these have been positively correlated with serum androgen levels (46). AGEs seem to contribute to the elevated risk of diabetes and cardiovascular disease in the general population (45). Moreover, insulinresistant PCOS women have increased levels of both serum AGEs and their respective receptor (RAGE), localized in theca and granulosa cells (46), suggesting a putative direct action of AGEs on ovarian function.

Interestingly, women with classic PCOS phenotype have higher serum AGEs levels than ovulatory PCOS women, indicating that AGEs are associated with the phenotypical severity (46). AGEs are related to the number of oocytes and pregnancy rates in PCOS women (47).

It is important to underline that the environmental source of AGEs can be reduced by diet modifications that lead to a decrease on oxidative stress markers as well as serum testosterone levels (48).

\section{CONCLUSIONS}

Overall, the data reviewed in this article demonstrate that EDCs contribute to numerous human female reproductive disorders. The effects of EDCs depend on the mechanism of action, the dose, and the period of life in which exposure occurred. There are many research gaps that limit full understanding of the real role of EDCs on female reproductive abnormalities. Moreover, knowledge of opportunity windows is important, not only for understanding the pathophysiological factors involved in the susceptibility to various diseases, but also for the creation of mechanisms to minimize the exposure of populations. There is an urgent need to reduce the incidence of these reproductive disorders, which can be addressed by studies correlating early-life 
exposure and adult reproductive dysfunction. Finally, it is a matter of concern that the endocrine disrupting potential of the majority of chemicals in production, including those that are found in common consumer products, has not been assessed systematically in regard to their effects on reproduction.

Disclosure: no potential conflict of interest relevant to this article was reported.

\section{REFERENCES}

1. Bachega TASS, Verreschi IT, Frade EMC, D'Abronzo FH, LazarettiCastro M. The environmental endocrine disruptors must receive the attention of Brazilian endocrinologists. Arq Bras Endocrinol Metab. 2011;55(2):175-6.

2. Decherf S, Demeneix BA. The obesogen hypothesis: a shift of focus from the periphery to the hypothalamus. JToxicol Environ Health B Crit Rev. 2011;14(5-7):423-48.

3. Schug TT, Janesick A, Blumberg B, Heindel JJ. Endocrine disrupting chemicals and disease susceptibility. J Steroid Biochem Mol Biol. 2011;127(3-5):204-15.

4. Christensen BC, Marsit CJ. Epigenomics in environmental health. Front Genet. 2011;2:84.

5. Diamanti-Kandarakis E, Bourguignon JP, Giudice LC, Hauser R, Prins GS, Soto AM. Endocrine-disrupting chemicals: an Endocrine Society scientific statement. Endocr Rev. 2009;30(4):293-342.

6. Zoeller RT. Endocrine disruptors: do family lines carry an epigenetic record of previous generations' exposures? Endocrinology. 2006;147(12):5513-4.

7. Hao C, Cheng X, Xia H, Ma X. The endocrine disruptor mono(2-ethylhexyl) phthalate promotes adipocyte differentiation and induces obesity in mice. Biosci Rep. 2012;32(6): 619-29.

8. Chang JW, Chen HL, Su HJ, Liao PC, Guo HR, Lee CC. Dioxin exposure and insulin resistance in Taiwanese living near a highly contaminated area. Epidemiology. 2010;21(1):56-61.

9. Liem AK, Fürst $P$, Rappe $C$. Exposure of populations to dioxins and related compounds. Food Addit Contam. 2000;17(4):241-59.

10. Casals-Casas C, Desvergne B. Endocrine disruptors: from endocrine to metabolic disruption. Annu Rev Physiol. 2011;73:13562.

11. Hayes TB, Anderson LL, Beasley VR, de Solla SR, Iguchi T, Ingraham $\mathrm{H}$, et al. Demasculinization and feminization of male gonads by atrazine: consistent effects across vertebrate classes. J Steroid Biochem Mol Biol. 2011;127(1-2):64-73.

12. Bigsby R, Chapin RE, Daston GP, Davis BJ, Gorski J, Gray LE, et al. Evaluating the effects of endocrine disruptors on endocrine function during development. Environ Health Perspect. 1999;107(4):613-8.

13. Fortes EM, Malerba MI, Luchini PD, Sugawara EK, Sumodjo L, Ribeiro Neto LM, et al. [High intake of phytoestrogens and precocious thelarche: case report with a possible correlation]. Arq Bras Endocrinol Metab. 2007;51(3):500-3.

14. Buttke DE, Sircar K, Martin C, et al. Exposures to endocrinedisrupting chemicals and age of menarche in adolescent girls in NHANES (2003-2008). Environ Health Perspect. 2012;120:1613-8.

15. Patisaul HB. Effects of environmental endocrine disruptors and phytoestrogens on the kisspeptin system. Adv Exp Med Biol. 2013;784:455-79.

16. Mouritsen A, Aksglaede L, Sørensen K, Mogensen SS, Leffers H, Main KM, et al. Hypothesis: exposure to endocrine-disrupting chemicals may interfere with timing of puberty. Int $\mathrm{J}$ Androl. 2010;33:346-59.

17. Guillette LJ Jr, Gross TS, Masson GR, Matter JM, Percival HF, Woodward AR. Developmental abnormalities of the gonad and abnormal sex hormone concentrations in juvenile alligators from contaminated and control lakes in Florida. Environ Health Perspect. 1994;102(8):680-8.

18. Hunt PA, Koehler KE, Susiarjo M, Hodges CA, llagan A, Voigt RC, et al. Bisphenol a exposure causes meiotic aneuploidy in the female mouse. Curr Biol. 2003;13(7):546-53.

19. Eichenlaub-Ritter U, Vogt E, Cukurcam S, Sun F, Pacchierotti F, Parry J. Exposure of mouse oocytes to bisphenol A causes meiotic arrest but not aneuploidy. Mutat Res. 2008;651(1-2):82-92.

20. Nelson LM. Clinical practice. Primary ovarian insufficiency. N Engl J Med. 2009;360(6):606-14.

21. Cooper AR, Baker VL, Sterling EW, Ryan ME, WoodruffTK, Nelson LM. The time is now for a new approach to primary ovarian insufficiency. Fertil Steril. 2011;95(6):1890-7.

22. Kirigaya A, Kim H, Hayashi $S$, Chambon $P$, Watanabe $H$, Lguchi $T$, et al. Involvement of estrogen receptor beta in the induction of polyovular follicles in mouse ovaries exposed neonatally to diethylstilbestrol. Zoolog Sci. 2009;26(10):704-12.

23. Newbold RR, Jefferson WN, Padilla-Banks E. Prenatal exposure to bisphenol $A$ at environmentally relevant doses adversely affects the murine female reproductive tract later in life. Environ Health Perspect. 2009;117(6):879-85.

24. Brieño-Enríquez MA, Reig-Viader R, Cabero L, Toran N, Martínez F, Roig I, et al. Gene expression is altered after bisphenol A exposure in human fetal oocytes in vitro. Mol Hum Reprod. 2012;18(4):171-83.

25. Ahn HJ, An BS, Jung EM, Yang H, Choi KC, Jeung EB. Parabens inhibit the early phase of folliculogenesis and steroidogenesis in the ovaries of neonatal rats. Mol Reprod Dev. 2012;79(9):626-36.

26. Hoyer PB, Devine PJ, Hu X, Thompson KE, Sipes IG. Ovarian toxicity of 4-vinylcyclohexene diepoxide: a mechanistic model. Toxicol Pathol. 2001;29(1):91-9.

27. Kappeler CJ, Hoyer PB. 4-vinylcyclohexene diepoxide: a model chemical for ovotoxicity. Syst Biol Reprod Med. 2012;58(1):57-62.

28. Cummings AM. Methoxychlor as a model for environmental estrogens. Crit Rev Toxicol. 1997;27(4):367-79.

29. Gaido KW, Maness SC, McDonnell DP, Dehal SS, Kupfer D, Safe S. Interaction of methoxychlor and related compounds with estrogen receptor alpha and beta, and androgen receptor: structure-activity studies. Mol Pharmacol. 2000;58(4):852-8.

30. Martinez EM, Swartz WJ. Effects of methoxychlor on the reproductive system of the adult female mouse. Gross and histologic observations. Reprod Toxicol. 1991;5(2):139-47.

31. Newbold RR. Lessons learned from perinatal exposure to diethylstilbestrol. Toxicol Appl Pharmacol. 2004;199(2):142-50.

32. Chao HR, Wang SL, Lin LY, Lee WJ, Papke O. Placental transfer of polychlorinated dibenzo-p-dioxins, dibenzofurans, and biphenyls in Taiwanese mothers in relation to menstrual cycle characteristics. Food Chem Toxicol. 2007;45(2):259-65.

33. Axmon A, Rylander L, Strömberg U, Hagmar L. Altered menstrual cycles in women with a high dietary intake of persistent organochlorine compounds. Chemosphere. 2004;56(8):813-9.

34. Farr SL, Cooper GS, Cai J, Savitz DA, Sandler DP. Pesticide use and menstrual cycle characteristics among premenopausal women in the Agricultural Health Study. Am J Epidemiol. 2004;160(12):1194204.

35. Nikaido Y, Yoshizawa K, Danbara N, Tsujita-Kyutoku M, Yuri T, Uehara $N$, et al. Effects of maternal xenoestrogen exposure on development of the reproductive tract and mammary gland in female CD-1 mouse offspring. Reprod Toxicol. 2004;18(6):803-11. 
36. Rubin BS, Lenkowski JR, Schaeberle CM, Vandenberg LN, Ronsheim PM, Soto AM. Evidence of altered brain sexual differentiation in mice exposed perinatally to low, environmentally relevant levels of bisphenol A. Endocrinology. 2006;147(8):3681-91.

37. Bastos AM, de Souza Mdo C, de Almeida Filho GL, Krauss TM, Pavesi T, da Silva LE. Organochlorine compound levels in fertile and infertile women from Rio de Janeiro, Brazil. Arq Bras Endocrinol Metabol. 2013;57(5):346-53.

38. Takeuchi T, Tsutsumi O, Ikezuki $Y$, Takai $Y$, Taketani $Y$. Positive relationship between androgen and the endocrine disruptor, bisphenol $A$, in normal women and women with ovarian dysfunction. Endocr J. 2004;51:165-9.

39. Zhou W, Liu J, Liao L, Han S, Liu J. Effect of bisphenol A on steroid hormone production in rat ovarian theca-interstitial and granulosa cells. Mol Cell Endocrinol. 2008;283:12-8.

40. Hanioka N, Jinno H, Nishimura T, Ando M. Suppression of malespecific cytochrome P450 isoforms by bisphenol A in rat liver. Arch Toxicol. 1998;72:387-94.

41. Fernández $M$, Bourguignon $N$, Lux-Lantos $V$, Libertun $C$. Neonatal exposure to bisphenol $A$ and reproductive and endocrine alterations resembling the polycystic ovarian syndrome in adult rats. Environ Health Perspect. 2010;118:1217-22.

42. Alonso-Magdalena $P$, Morimoto $S$, Ripoll C, Fuentes E, Nadal A. The estrogenic effect of bisphenol A disrupts pancreatic beta-cell function in vivo and induces insulin resistance. Environ Health Perspect. 2006;114:106-12.
43. Kandaraki E, Chatzigeorgiou A, Livadas S, Palioura E, Economou $F$, Koutsilieris $M$, et al. Endocrine disruptors and polycystic ovary syndrome (PCOS): elevated serum levels of bisphenol $A$ in women with PCOS. J Clin Endocrinol Metab. 2011;96:E480-4.

44. Pasquali R, Stener-Victorin E, Yildiz BO, Duleba AJ, Hoeger $\mathrm{K}$, Mason $\mathrm{H}$, et al. PCOS Forum: research in polycystic ovary syndrome today and tomorrow. Clin Endocrinol (Oxf). 2011;74:424-33.

45. Uribarri J, Tuttle KR. Advanced glycation end products and nephrotoxicity of high-protein diets. Clin J Am Soc Nephrol. 2006;1:1293-9.

46. Diamanti-Kandarakis E, Katsikis I, Piperi C, Kandaraki E, Piouka A, Papavassiliou AG, et al. Increased serum advanced glycation end-products is a distinct finding in lean women with polycystic ovary syndrome (PCOS). Clin Endocrinol (Oxf). 2008;69:634-41.

47. Jinno M, Takeuchi M, Watanabe A, Teruya K, Hirohama J, Eguchi $\mathrm{N}$, et al. Advanced glycation end-products accumulation compromises embryonic development and achievement of pregnancy by assisted reproductive technology. Hum Reprod. 2011;26:604-10.

48. Diamanti-Kandarakis E, Piouka A, Livadas S, Piperi C, Katsikis I, Papavassiliou AG, et al. Anti-mullerian hormone is associated with advanced glycosylated end products in lean women with polycystic ovary syndrome. Eur J Endocrinol. 2009;160:847-53.

49. Costa EMF, et al. Desreguladores Endócrinos. In: Proendócrino. vol. 4. Porto Alegre: Artmed Panamericana; 2013. 